\title{
Identifying the characteristics of support Australian university teachers use in their design work: Implications for the learning design field
}

Shirley Agostinho

School of Education, Faculty of Social Sciences, University of Wollongong

Lori Lockyer

Graduate Research School, University of Technology Sydney

Sue Bennett

School of Education, Faculty of Social Sciences, University of Wollongong

Quality teaching is a strategic objective for universities; thus, there is an expectation that university teachers design high quality learning experience for their students. The field of learning design has developed over the past 15 years as a way to support teachers in their design work. There has been significant research and development work that has focused on creating support tools to help teachers plan, develop and deliver learning experiences. However, little is known about what supports teachers access and use when they design and overall how teachers undertake their design work. This paper presents the findings from a qualitative study that investigated the types of supports 30 teachers from 16 Australian universities reported using in their design work. Data was collected from semi-structured interviews, and the results show that participants accessed a variety of supports depending on their design need. The kind of support participants accessed in their design work were colleagues, literature, workshops and seminars, conferences, institutional support services, and enrolment in postgraduate study. How participants explained using these supports can be characterised as varied, personalised, dynamic and networked. Based on these results, implications for the learning design field are discussed with recommendations for future research.

\section{Introduction}

Designing learning experiences for students is a routine yet important aspect of a university teacher's role. The context of teaching in higher education, however, has become increasingly complex, with changes in the profile and needs of learners, expectations that institutions will offer flexible modes of delivery, and greater accountability for high quality educational experiences.

The social and economic circumstances of full-time students have challenged traditional notions of the typical student (James, Bexley, Devlin, \& Marginson, 2007; Krause, Hartley, James, \& McInnis, 2005). Choice of course and university, family and social commitments and financial circumstances mean that full-time students may be commuting to attend classes, engaging in part-time work and demanding more flexibility in their study schedule. University teachers are expected to cater for this need for flexibility and understanding of student circumstances in the design of their units/subjects (hereafter referred to as unit, which represents a component of a program of study that leads to the award of a degree). At the same time, Western countries are seeking to build capacity within the knowledge-based economy by setting new targets for higher education enrolments. For example, if goals for 2020 in Australia are reached there will be considerably more students enrolled in universities and colleges - particularly students from lower socioeconomic backgrounds (Bradley, Noonan, Nugent, \& Scales, 2008). This means teachers will need to plan for larger classes with an increasingly diverse student cohort.

The use of technology is seen as one answer in addressing issues relating to offering flexible learning opportunities, catering for student diversity and larger student cohorts, and overall providing a high quality learning experience. Moreover, teaching with and about technology is seen as essential to engaging learners 
and preparing students for their future careers. Technology is often coupled with words such as "transformational" and "revolutionary" and has become a significant component of strategic decision-making and policy agendas for higher education (Glenn, 2008).

There has been significant government investment in Australia to support quality teaching and learning under the auspices of a national funding body - the Office of Learning and Teaching (OLT) and its predecessors. One particular initiative that emerged from such funding with the specific intention of supporting teachers to design high quality learning experiences that include the use of technology is the field of learning design.

Learning design, a field that has developed over the past 15 years, has focused on developing support tools to help teachers plan, implement and revise learning experiences for their students. Support tools have taken the form of practice examples and design process tools. The rationale of a practice example is that it can capture the pedagogical intent of a design by documenting the sequence of intended learning experiences. Thus, if teachers have ready access to best-practice examples, documented in a way that teachers can easily understand, the assumption is that teachers would be able to transfer those examples into their own context. This has led to a range of research work investigating different ways practice examples can be represented (e.g., Agostinho, 2009, 2011; Conole \& Wills, 2013; Laurillard, 2012; McAndrew \& Goodyear, 2013) as well as how online repositories could be used by teachers to share and thus reuse other teachers' practice examples (e.g., Agostinho, 2009; Bergin et al., 2012; Conole \& Culver, 2010). Design process tools are intended to support teachers' thinking as they create, implement, and revise learning experiences. Two examples that illustrate the research and development work of online tools to support teachers' design process are the integrated learning design environment (Hernández-Leo, Asensio-Pérez, Derntl, Prieto, \& Chacón, 2014), which provides a range of tools to support the co-creation, sharing, and delivery of learning designs; and the Learning Design Support Environment (Laurillard et al., 2013), which serves as a support tool for teachers to use digital technologies effectively in their teaching.

This research and development work in learning design has shone light on the potential benefits that these support tools can have to guide teachers' design decisions and processes. This has paradoxically led to a greater understanding of what is not known about how university teachers undertake their design work. The insights gained from learning design research has enabled more questions to be asked, namely: How do such support initiatives align with teachers' current design practices? Whilst it is recognised from broader research that the design of high quality teaching leads to high quality student learning (Ramsden, 2003; Trigwell, Prosser, \& Waterhouse, 1999), surprisingly little is known about how teachers design. This presents challenges in determining how to optimally support university teachers' design practices. Thus, there is a need for broader investigation into understanding how university teachers conduct their design work to learn more about what processes university teachers follow when they design, what influences teachers' design decisions, and what kinds of support they use in their design work. The research team embarked on such a study, which investigated how Australian university teachers design learning experiences for their students. This paper presents the findings from one component of this broad study, which focused on identifying the types of support Australian university teachers reported accessing and using in their design work (see Bennett, Agostinho, \& Lockyer, 2016a, for an explanation of the broad research study; and Bennett, Agostinho, \& Lockyer, 2015, 2016b, for results from the other components of this study).

\section{Methodology}

To investigate the types of supports teachers used in their design work, a qualitative research design in the form of semi-structured interviews was implemented. Data comprised of participant responses to a semistructured interview that was between 50 and 90 minutes in duration. A qualitative approach was deemed appropriate as the focus of this study was to gain understanding about a phenomenon; that is, how teachers go about their design work, of which little is known.

There were 30 participants: 25 were interviewed by telephone and five participants were interviewed face-toface. The interview protocol was designed to capture a teacher's account of their existing design practices. As 
such, questions were open-ended in nature allowing participants to explain and elaborate on their past design experiences. Participants were asked about their teaching context (such as where they worked and what units, year levels, and topic areas they taught), their conception of teaching in their discipline, their approach to designing new units and revising existing ones, what influenced their design decisions, and from where they sourced their design ideas. The interview questions were informed from empirical research that examined university teachers' planning processes and decision-making. Examples of such research are Stark (2000), who explored the decision-making processes of American college teachers during planning of first-year units; Prosser and Trigwell (1997), who examined how Australian university teachers' perceptions of their teaching environment influence their teaching approach; and Postereff and Lindblom-Ylänne (2008), who identified variations in the teaching processes of Finnish university teachers. Approval was obtained from the authors' institutional Ethics Committee before participant recruitment commenced. All interviews were audio recorded and transcribed verbatim. Transcripts were emailed to participants to enable them to check them for accuracy.

Participants were recruited by email invitation through professional organisations focused on higher education. Those who responded to the email invitation were asked to complete a number of screening questions which allowed for purposive sampling on the basis of the study's criteria: discipline; years of teaching experience in university, year levels taught, and type of teaching delivery, that is, face-to-face and/or online. Participation was limited to academic staff holding teaching and research responsibilities in faculties; thereby excluding research-only faculty members or academic staff located in teaching and learning support units. Of those who volunteered, 30 participants were chosen. These participants represented diversity across the four criteria and equally represented broad discipline groupings, that is, the Sciences, The Arts and the Professions, based on the higher education discipline groups from the Australian Bureau of Statistics (2001) and Shulman's (2005) work on signature pedagogies. Furthermore, as this was intended to be an Australiawide study, participants were drawn from 16 of the 40 Australian public universities representing the spectrum of research and teaching oriented institutions.

An analysis framework was developed based on the literature, which informed the interview protocol and an initial reading of the data by the six-member research team. Each interview transcript was assigned to two members of the research team for independent coding using this analysis framework. A comparison of coding for each interview revealed discrepancies that were then used to revise or extend definitions in the analysis framework document or re-assign codes until consensus was reached within the team. This resulted in the consolidation of some codes and re-structuring of the code hierarchy. The analysis framework comprised seven high level codes: context, teaching approach, design context, online learning, process, design influences and support. Each of these codes included sub-codes, and all were accompanied with definitions and sample quotes (see Bennett et al., 2016b, for a more detailed explanation of the generation of codes).

This paper presents the findings related to the support code. This code focused on the sources university teachers reported they drew on to support their design work. Table 1 provides a description of the sub-codes within the Support code. The data set for this code surfaced from several open-ended questions asked in the interview. The semi-structured nature of the interview allowed participants to report in depth about how they undertook their design work. Example questions included "When you've designed a unit from scratch/modified an existing unit, where do you start? What do you do next? What were the main challenges for you? From where do you source your ideas? How do you decide on the structure of the unit/assessment /content to include?” Qualitative analysis software generated sub-code reports that were reviewed to identify themes and patterns. A summary table was then compiled (see Table 1) that tabulated individual participant responses according to each theme so that a comparison could be made of participants within and across disciplines. 
Table 1

Sub-codes within the support code

\begin{tabular}{ll}
\hline Sub-code & Definition \\
\hline Colleagues & $\begin{array}{l}\text { Spontaneous discussions/chats with colleagues about teaching ideas; } \\
\text { Deliberate discussions/meetings with colleagues to discuss/develop } \\
\text { teaching ideas/skills }\end{array}$ \\
$\begin{array}{l}\text { Conferences } \\
\text { Institutional provided support }\end{array}$ & $\begin{array}{l}\text { Accesses central support units to assist with design work; includes } \\
\text { educational design and technical support }\end{array}$ \\
Literature & Searches literature to support design ideas \\
Workshops and seminars & Attends workshops to develop teaching skills \\
Other & Accesses other forms of support not specified in the other sub-codes \\
\hline
\end{tabular}

\section{Results}

Of the 30 participants in the study, 11 were from the Sciences, 10 from the Arts and Humanities, and 9 from the Professions. There were 16 females and 14 males. The majority of participants (23 of 30) had more than 10 years of teaching experience, four participants had taught between 5 and 10 years, and three participants had fewer than 5 years of teaching experience. Half (15) of the participants taught at both the undergraduate and postgraduate levels; 14 taught at only the undergraduate level; while only one participant taught only at the postgraduate level. At the time of the study, most participants (26) taught units that combined face-to-face and online, three taught units that combined online and print-based distance education, and one taught only face-to-face classes. The sources of support participants reported that they accessed are presented below in order of dominance.

\section{Supports used}

\section{Colleagues}

Colleagues were considered a key design support. Most participants (25 of 30; 83\%; 8 Arts, 8 Professions, 9 Sciences) discussed teaching ideas with their colleagues within their own university and/or at other institutions. Such discussions occurred through deliberate planning or more serendipitously.

The more spontaneous types of interactions with colleagues included unscheduled chats within and outside their institution and/or being shown a particular technical skill by a colleague. For example, Gloria (Sciences) said she sourced ideas by simply "talking to other people about what they're doing in their classes”. Belinda (Sciences) said she sourced ideas from "conversations in the staff room ... in the hallways" and Joyce (Professions) said an excellent source of information was "just chatting in the corridors”. Debbie (Sciences) explained the informal nature of her discussions with colleagues:

I get a lot of ideas by talking to [colleagues], not necessarily in any formal way it's just, you know, "I've got this unit to do and ... I was thinking of doing such and such but ... that's a bit boring and I'm looking for ideas”.

Eight participants (3 Arts, 2 Professions, 3 Sciences) explained they established their own colleague networks either within or outside their institution to discuss and share teaching ideas. The quotes below illustrate these participants' self-initiated collegial support structures:

There's an ongoing discussion with my colleagues .... it's not so much that I sit down to design the course and say, alright I'm going to go out and seek some advice from colleagues, it's more that there's that kind of discussion going on all the time. (Steve, Arts) 
I know a lot of people ... a lot of us talk about these sort of things all the time. (Craig, Professions)

I have many colleagues who teach similar units at other universities, so it's quite an easy and an important exercise to ... chat with them and find out what they are doing. (Katrina, Arts)

I have a network of colleagues, some of whom are former students of mine ... but we're still in touch and we've become very, very close friends and there's probably half a dozen of us in the [geographic location removed] area and we meet regularly and I regularly bounce ideas from them ... that's peer review. (Debbie, Sciences)

Participants thought that the opportunity to have a colleague demonstrate a particular technology-based skill to use in their teaching was very helpful. For example, Christine (Arts) commented how she was able to confidently implement a technology skill after being shown by her colleague: "She'd show me something that she was doing and then I'd go off and do my little bit and ring her up and say, oh look, I did that, that works really well”. Another participant, Trent (Arts), explained how providing technical support to colleagues was formalised in his department in the form of a mentoring role:

We're talking a lot in the school ... about design ... particularly blended learning design ... I've now become a mentor ... So that's been me being a resource for other academics ... I go around and talk ... find out what they're doing ... and what they're thinking about.

More deliberate and planned discussions with colleagues included scheduling teaching team meetings and/or providing opportunities so that teaching teams could share ideas. For example, George (Arts) explained he often met with staff involved in a unit to discuss: "What do you feel about [the unit] and did that work or did it not? And then we might ... suggest some modifications to it for next time round”. Deidre (Sciences) described how her teaching team worked together to discuss and critique their teaching:

We have a book ... and people can write their ideas in it or corrections in the manual and then at the end of session we have a debriefing where all the staff involved in a subject get together and we have cake and coffee and we go through each practical that we did and we talk about the positives and the negatives and how we can make it better. We talk about the lecture material, we talk about problems we've had individual students or cohorts may have had so we can try and address those next year.

A few participants (3: 2 Professions, 1 Sciences) mentioned that membership in professional networks and associations served as an opportunity to discuss teaching ideas: "We are all members of several outside associations ... so when we are at meetings we have good relations ... so we get a lot of ideas...from our peers” (Bill, Professions).

Overall, these results show that participants valued colleagues as a high quality form of support. Colleagues were considered as credible sources of support because they were peers working in a similar context, for example, a fellow teaching academic located in close proximity (such as working in the same location, department, or faculty); or working in the same institution in another faculty; or teaching similar units, be it within the same institution or in other institutions. A theme that surfaced about seeking support from colleagues was credibility. As one participant commented: "The best source of ideas is colleagues that are just better than me at things" (Shane, Arts).

\section{Literature}

Two thirds of participants (20 of 30; 7 Arts, 6 Professions, 7 Sciences; 66\%) stated they accessed literature as a form of design support. Participants reviewed the literature to gain ideas about teaching and learning in general, to learn more about specific teaching strategies, and review discipline-specific literature about the content areas in which they teach. Overall, there was an even split between participants who referred to accessing education-based literature and those who reported accessing discipline-specific content-based 
literature (with an even distribution of discipline group for each). Specifically, there was three reasons participants reviewed literature: keep up-to-date with teaching and learning ideas in general; adapt other people's ideas in their own teaching; and form an evidence base to justify design decisions. These are elaborated as follows.

Several participants reported they referred to the literature on a regular basis to keep up to date on the latest ideas for teaching and learning. For example, Darren (Sciences) said his ideas came "from my increased understanding in reading ... I'm reading a little bit of educational literature ... at the moment I'm reading about communities of practice” and Lily (Professions) said: "I do try and read regularly". Factors such as time and the focus of certain literature were noted as constraints of the usefulness of this type of support. For example, Cameron (Professions) explained why time was a limitation: "I read the teaching and learning articles but once a session is on I hardly get time to even look at that kind of stuff". Another limitation was the ability to translate ideas from the literature into practice:

There's this huge gap between the sort of cutting edge technology ... in ... educational journals ... and what is actually happening at the ... teaching coalface. We don't want to be as cutting edge as some of this journal stuff is but we want to do something and the gap there is too big. (Christine, Arts)

Reading literature to adapt other people's ideas in their own teaching was a reason mentioned by two participants (both from Sciences). For example, this was explicitly explained by Belinda (Sciences): "reading articles about other people's examples ... and looking at what can be taken from what somebody else might be doing and ... can I adapt that to what I'm doing?”.

Participants spoke about reading literature to justify design decisions. It was considered important to have a sound understanding of the education-based literature to support design decisions, particularly when a new strategy or approach is being implemented. For example, Gloria (Sciences) explained she reviewed the literature to support her decision about a form of assessment:

Take the question of choosing not to use multi-choice for the whole of the final exam, and something else instead, what's my justification? Well, I'm going to have to fish deeply into what information I can find on education and theory in practice, which would justify what I'm going to do for two reasons ... I want to know why I want to go down a path that's going to involve more resources, but also if I'm going to go down that path, I'd better make sure I go down the right one.

George (Arts) reported he conducted a literature review to support his ideas about changing his assessment practices. He explained that he reviewed "the literature on assessment practice ... to find ways then to actually bring that in and contextualise it within our structures". He went on to say he presented a paper at a conference about how he had implemented this new assessment practice.

\section{Institutional support services}

Central support services are structured in various ways in universities. In some cases, teaching, learning and technology support are combined and provided from one department; in other institutions, technology support is separate from teaching and learning development for staff. Generally, participants in this study did not make distinctions in terms of how these services were structured, but did discuss the nature of the support that they accessed and received through centrally provided services.

Just over half of the participants (17 of 30) referred to receiving some kind of support from central support services. The type of educational support included:

- general ideas about teaching through one-on-one informal contact

- $\quad$ specific advice on the redesign of a unit of study 
- development of teaching materials

- $\quad$ peer review of teaching or materials developed by participants

- $\quad$ support for writing a teaching development grant application

- collaboration on a funded teaching development grant.

The type of technical support received by participants ranged from just-in-time phone-based support about learning platforms tools such as an institution's learning management system to more tailored project-based technical support, for example, programming expertise to develop a particular technology application used in a unit.

Participants who did draw on central teaching, learning and technology support services generally held positive perceptions of this form of support. However, some mentioned limitations with this kind of support. Four participants (2 Arts, 2 Sciences) commented they were sometimes sceptical about the advice they received on specific issues from central support services staff because the support staff often did not have much direct university teaching experience. For example, Kirk (Arts) commented that workshops delivered by non-teaching staff who do not fully understand an academic teacher's context were not very helpful: "they're normally given by people who don't actually engage in undergraduate teaching, who don't actually do what lecturers do". Kerrie (Arts) provided a similar sentiment: "if that person hasn't taught a hundred plus ... students ... I don't find it very helpful to have their suggestions as to what might work well”.

Another four (2 Arts, 2 Professions) of the 17 participants who accessed central support services noted that organisational restructures in such departments seemed to result in high staff turnover, which caused confusion as to who could provide support and the extent of available support. For example, Christine (Arts) commented: "It's very complicated to make sure you're asking the right person the right question".

\section{Workshops and seminars}

Just over half of participants (16 of 30) stated that they had attended workshops and/or seminars as a form of support for their teaching. These were seminar-based and focused on academics presenting their experiences with particular issues or strategies (e.g., assessment, problem-based learning) or workshops that aimed to develop particular teaching or technology skills (such as conducting large group lectures, using the learning management system or Web 2.0 tools such as blogs and wikis). Three (2 Arts, 1 Sciences) of the 16 participants noted they accessed this type of support more so when they were new to their institution: "I had to attend sessions when I started teaching here" (Steve, Arts); or in the early stages of their academic career: "When I first started teaching ... I went to every single PD [professional development] that I could get my hands on" (Debbie, Sciences).

Five participants (3 Arts, 1 Professions, 1 Sciences) reported that they found workshops and seminars useful as a design support and they had used some of the ideas and skills in their teaching. However, two of these participants noted that what was covered in the workshops was often not relevant to their teaching context. For example, Steve (Arts) explained:

Often you'll go to a seminar about why aren't the students turning up at my lectures and they'll be all sorts of ideas about how you can fix that, but an awful lot of them won't be relevant to your particular case because your cohort of students are different.

One of these five participants highlighted that an added benefit of a workshop or seminar was the opportunity to meet teaching academics from other schools and faculties:

I find that a really good source of sharing information with other staff members. Thinking of different ways of doing things, not only from the people who are presenting the workshop but by the people who attend. (Trent, Arts) 
Another five participants (1 Arts, 4 Sciences) thought that workshops offered limited support because they were either too general or too time consuming. For example, Belinda, an experienced teacher in the Sciences, said:

I'm a little bit dubious about workshops because ... I've had far too many experiences of twoday workshops, and then by the time you get back to your office and try catch up with your email, you have forgotten three quarters of it by the time you get around to try to implement it.

Overall, the theme that runs throughout these findings is that university teachers seek and place value in the experiences of fellow teaching colleagues, and that they access this kind of support in various forums, such as literature, workshops and seminars.

\section{Conferences}

Just under half of participants (14 of 30) thought attending conferences was a useful form of design support, namely because it enabled them to "hear how things are being done elsewhere" (Julie, Arts). Whilst participants mentioned attending discipline- or research-focused conferences, most said they discussed teaching ideas and exchanged resources with colleagues as an incidental networking activity, which may not have been the primary focus of the conference. Two participants explained the nature of their collegial discussion that occurred at discipline-based conferences:

I mean, often when you go to conferences ... there's a lot of teaching-based discussion and you would ... come back inspired by other people's ideas and try to integrate them into your work into teaching. (Katrina, Arts)

Quite often academics from various areas get together and we talk about what we're doing and what we're teaching and we quite often swap lecture notes. (Deidre, Sciences)

Some participants (1 Arts, 2 Professions, 1 Sciences) explained attending conferences focused on teaching in higher education and/or educational technology. Lola (Sciences) thought presenting her teaching ideas served as a useful form of support:

I think that's the other inspiration, you're preparing for these conferences and writing something about your teaching and so on and then you read other people's work and you start to realise there's quite a lot of different developments happening. (Lola, Sciences)

Overall, participants thought that conferences were useful for sharing teaching ideas. This provides further evidence of the value participants placed on colleagues as a form of support.

\section{Online teaching resources}

Nine participants (4 Arts, 3 Professions, 2 Sciences) reported regularly accessing teaching-focused resources online. Three participants referred to browsing the web for ideas or resources, or to find help on how to use an online tool. One experienced teacher in the Arts explained:

I don't follow journals, for example, but I do browse online for ideas that other people are trying out. So some of the new ideas that I've had, things that I might want to try in the future have come from videos that are on YouTube about teaching, things that come from online sites where e-learning is discussed. People say "I tried this and it worked" and I think "oh yeah I think that would work here”. So I don't ... take a kind of thorough approach to this ... but I browse around to see what people are doing. (Kerrie, Arts)

Three participants (1 Arts, 1 Professions, 1 Sciences) explained how they found support for their teaching by being members of email discussion lists or forums. For example, Steve (Arts) explained he was a member of several online forums to see how those communities of practice work: 
I spend a lot of time looking at what people are doing online ... there are [discipline name removed] forums online which are very successful ... and so ... I was sort of looking at the community of practice that existed in those forums and thought ... wouldn't that be great to be able to develop a similar ... community of practice in [unit name removed].

Two participants found institution-based subscription websites useful for teaching resources. For example, Kathleen (Professions) explained, "We're a member of this online learning university-type conglomerate all over the world and you can actually go in and have a look at what [institution name removed] are doing ... and just take what works for you".

\section{Further formal study}

Some participants spoke about how their institutions encouraged academic staff to engage in further study about teaching. One participant mentioned completing an institution-required introduction to tertiary teaching course. Another participant explained that her institution encouraged academic staff to enrol in a Graduate Certificate in Higher Education. Another three participants were undertaking further formal study to support their teaching: two were completing a Graduate Certificate in Higher Education, and one participant was undertaking an education-focused doctorate. This suggests that some participants sought support from formal study as a way to gain theoretical and evidence-based knowledge about teaching and learning.

\section{Summary of results}

From analysing participants' responses about the types of support they accessed and used in their design work, the way in which design supports were used can be characterised as varied, personalised, dynamic and networked. In describing their experiences, each participant drew on a variety of sources to support their design work. The selection of supports used by each participant was personalised to suit their context. The type and mix of the supports used changed over time, depending on an individual's career stage and circumstances. There was a sense in which the supports used were those that were appropriate for an individual at a particular time in a particular place. This suggests that teachers use design supports in a dynamic way. Overall, the nature of supports that resulted was inherently social, comprising a network of colleagues, both local and distant, and drawing on the work of others. Despite the varied types of supports (e.g., talking with colleagues, reading literature, or attending a workshop, seminar or conference), a key theme that surfaced about the nature of these supports is their networked affordability; that is, drawing connections with other people's teaching and learning ideas. Taken together, the array of supports available forms an ecosystem that individuals selectively draw on to meet their needs in particular contexts.

\section{Discussion}

To extend the above argument about support used by participants, we have identified a set of dimensions that can be used to characterise each type of support (see Figure 1). Each dimension is a continuum rather than a dichotomy. A type of support can be mapped qualitatively according to each dimension, allowing its characteristics to be differentiated.

An example to help define and exemplify the characteristics of design support, Figure 2 maps the dimensions of two different types of supports identified by our participants. One source of support is attendance at a workshop offered by a central teaching and learning unit in a teacher's university, which is focused on applying a particular teaching approach such as problem-based learning (W). The other source of support involves a teacher browsing the discipline-based teaching literature to look for new ideas (L). Each dimension is elaborated as follows.

As identified, all forms of support that participants reported they drew upon in their design work were inherently social; that is, they involved teachers interacting with the ideas and practices of others. However, there were varying extents to this interaction and this is characterised on the social dimension. In our examples, at the lower end of the continuum a teacher interacts with the ideas of authors by reading the 
literature. In a workshop setting (represented at the higher end of the continuum) a teacher has the opportunity for direct multidirectional interaction with workshop facilitators and other participants.

All university teachers have control over their design work and control of the sources they use to support their design work. Our participants indicated that they engaged in both serendipitous and more planned types of activities to support their design work. The agency dimension can be used to characterise the extent of control and deliberate planning related to any one support. For example, browsing the literature involves a high level of agency with the teacher choosing to engage in the activity, how much time and how often to browse the literature, what sources to browse, what and how many articles to read. Whilst participating in a workshop has some level of agency, if the teacher voluntarily chooses to attend, the specific content, format, structure and facilitator of the workshop is likely beyond the teacher's control (and thus is represented at the lower end of the continuum).

\begin{tabular}{|c|c|c|}
\hline \multicolumn{3}{|c|}{ Social } \\
\hline Low & $\leftarrow-$ & High \\
\hline \multicolumn{3}{|c|}{ Agency } \\
\hline Low & $\leftarrow--$ & High \\
\hline \multicolumn{3}{|c|}{ Authority } \\
\hline Low & $\leftarrow$ & High \\
\hline \multicolumn{3}{|c|}{ Inspiration } \\
\hline Low & $\leftarrow$ & High \\
\hline \multicolumn{3}{|c|}{ Application } \\
\hline Low & $\leftarrow-$ & High \\
\hline \multicolumn{3}{|c|}{ Proximity } \\
\hline Low & 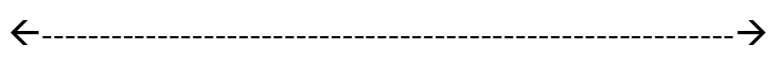 & High \\
\hline \multicolumn{3}{|c|}{ Synchronicity } \\
\hline Low & 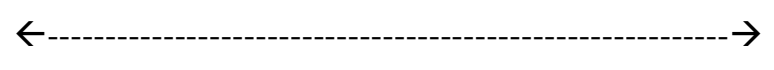 & High \\
\hline \multicolumn{3}{|c|}{ Recognition } \\
\hline Low & $\leftarrow-$ & High \\
\hline
\end{tabular}

Figure 1. Dimensions of design support used by university teachers 


\begin{tabular}{|c|c|c|}
\hline \multirow[b]{2}{*}{ Low } & Social & \multirow[b]{2}{*}{ High } \\
\hline & 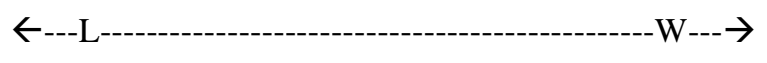 & \\
\hline \multicolumn{3}{|c|}{ Agency } \\
\hline Low & $\leftarrow---W-1$ & High \\
\hline \multicolumn{3}{|c|}{ Authority } \\
\hline Low & 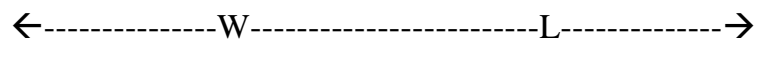 & High \\
\hline \multicolumn{3}{|c|}{ Inspiration } \\
\hline Low & $\leftarrow--1$ & High \\
\hline \multicolumn{3}{|c|}{ Application } \\
\hline Low & $\leftarrow$-L-1--1 & High \\
\hline \multicolumn{3}{|c|}{ Proximity } \\
\hline Low & $\leftarrow-$ L - - & High \\
\hline \multicolumn{3}{|c|}{ Synchronicity } \\
\hline Low & $\leftarrow--L---1$ & High \\
\hline \multicolumn{3}{|c|}{ Recognition } \\
\hline Low & 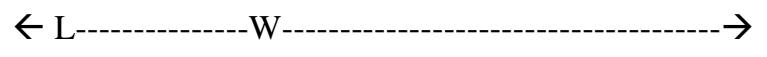 & High \\
\hline
\end{tabular}

Figure 2. Examples of specific design support used by university teachers per dimension

A key theme in our findings was that participants valued discussions with colleagues who work in a similar professional context. Participants considered their ideas, suggestions and advice as relevant and credible. However, participants did not necessarily limit their interest in others' ideas to those within their own discipline or in closely related disciplines. Overall, these findings suggest that university teachers value support from credible others. While we recognise the complexity in relation to this concept of credibility, the authority dimension helps to consider the value judgement a teacher might make about a particular source of support. In relation to our findings, participants thought that reading literature and attending workshops and seminars were useful types of supports (thus represented towards the middle of the continuum). Participants used the literature as a support to source published evidence-based knowledge (thus, this is represented more towards the higher end of the continuum). The usefulness of workshops was influenced by factors such as time and profile of staff running the workshops; thus, in terms of a value judgement about this particular source of support, it is represented more towards the lower-end of the continuum. It may be that the authority and agency dimensions are inextricably linked.

The inspiration and application dimensions help to characterise the purpose or focus of the support that teachers reported that they drew upon in their design work. Participants reported getting ideas or inspiration from a range of sources that helped to get them thinking about their designs. They also reported needing very specific support that they wanted to apply or to put their ideas into action. Reading the literature might be high on the inspiration dimension but low on application dimensions. Attending a workshop might be at midpoint on the inspiration continuum but high on the application continuum.

Participants in this study indicated that they drew design support from colleagues both within their immediate faculty, department or university and outside their institution. Proximity provides a way to characterise the immediacy of support, which might be high in the case of a workshop delivered within a teacher's institution and lower in the example of reading literature which may be authored by someone outside the teacher's university and for which access is mediated by a website, publisher or literature database service. 
The use of time was a concept that underpinned the choices of supports used by participants in their design work. For example, some participants said they accessed the literature regularly to keep up to date with current teaching and learning ideas and some found attending a workshop whilst useful to be time-consuming. Synchronicity is a way to characterise this aspect of time. Attending a workshop is a highly synchronous activity involving the teacher for a specified or defined period of time. Reading the literature is somewhat asynchronous, in that the individual can choose chunks of time to devote to this activity, and thus literature is lower on this continuum.

Recognition refers to the extent to which engagement in an activity that supports teachers in their design work is formally and/or externally acknowledged. In our two examples, browsing discipline-based literature would be on the lowest end of the continuum of recognition as it would be unlikely that anyone but the teacher themselves would be aware of or acknowledge this activity. However, participation in a workshop might be externally recognised with a certificate of attendance or logged on a professional development record. An example of a support reported by our participants, such as enrolment in a diploma of higher education, might be indicated on the highest end of the recognition continuum.

Working with these dimensions shows how there can be variation within a type of support. For example, the purpose of engaging in the workshop might be for inspiration rather than for understanding how to apply a particular approach. Likewise, searching the literature could be a strategy to locate particular examples that can be tailored to one's own context or to validate one's own approach. Also, depending on the nature of the workshop the experience may be highly social as a forum for sharing experiences and ideas, or much more individual where the experience is of receiving information. This simple exercise demonstrates that types of support do not necessarily have inherent characteristics, but can vary depending on how they are enacted or experienced.

These dimensions are helpful in beginning to distil the characteristics of different types of support. They are, however, by no means comprehensive. These dimensions serve as a preliminary conceptual framework to represent the findings from this study. Further research is required to validate and extend this framework to reveal additional dimensions or further subtleties and interlinking of the dimensions suggested above. These dimensions serve as a useful starting point from which to map the varied, personalised, dynamic and networked supports available to, and experienced by, university teachers.

The results presented in this paper add further insight to our broader study about the design practices of teachers in the following ways. Firstly, our broader work has found that Australian university teachers have a significant amount of freedom and flexibility in the decisions they make about their teaching (Bennett et al., 2011). This is corroborated in this study as our participants made decisions on what supports to source and how to use them to help and guide their design work. Secondly, a strong influence on the design decisions teachers make is the collegial context in which they work. We have found that design work is both an individual and social practice (Bennett et al., 2015). The nature of supports accessed by participants, as discussed above, also exhibited social qualities; thus, this provides additional evidence to this finding. Thirdly, our broader study has shown that the design process teachers undertake is iterative and context dependent (Bennett et al., 2016b). The results in this paper present a similar picture in terms of the supports teachers use. That is, the selection of supports used by each participant was dependent on their particular context. Our preliminary conceptual framework of support dimensions (Figure 2) illustrates this contextual nature.

Further research is required to build on the findings of this study that indicate teacher design work is informed by others and is highly contextual. As such, approaches that allow researchers to uncover the context in which teachers' work will go some way to help identify how teachers' design knowledge and skills can be developed and supported - importantly, how teachers may have agency in developing their design practice. Activity theory (Engeström, 2001) is one framework that provides an approach to identifying the internal (personal) and external (environmental) elements that interact to elaborate the ecosystem in which a teacher engages in their design work. Such as framework could be applied to observe teachers' design work over time. This 
would address a limitation of the study reported in this paper, where the dataset comprised one interview based on participants' recalled design experiences.

The idea of framing teachers' design work with both personal and environmental factors leads to implications for the field of learning design. Since its inception, the field has been focused on (and even named) by the nature of the output of teachers' work, that is, the design of an experience for learners. Rather, we contend that to achieve a high-quality experience for a learner, effort needs to be placed on understanding, in order to ultimately support, the design work of the teacher. The rationale for the supports used by teachers in their design work reported in this study closely resembles characteristics of design thinking. For example, our participants spoke about implementing teaching ideas gained from attending a workshop or reviewing literature. This demonstrates being responsive to new ideas and making design decisions, which are design thinking traits (Razzouk \& Shute, 2012). The above-mentioned example of a teacher reviewing literature to validate their own teaching approach is a backward (validating) reasoning strategy which is a design thinking characteristic (Razzouk \& Shute, 2012, p. 337). It is important to note that the majority of participants in this study had more than 10 years teaching experience; thus, their expertise may have influenced the evidence of design thinking characteristics. Both personal and environmental factors are social activities that involve the ideas and input of multiple others; they involve deliberate action but may also be influenced by serendipity. As such, we contend that addressing the challenge of improving learning in education requires a focus on understanding teacher design thinking.

\section{Conclusion}

The purpose of this study was to investigate what kinds of supports Australian university teachers access and use to help them with their teaching design work. The 30 participants involved in this study reported accessing different sources of support. These included colleagues, literature, workshops and seminars, conferences, institutional support services and involvement in postgraduate study. The kinds of supports used varied depending on the teacher's career stage and design need. Overall, design supports drawn from our participants can be characterised as varied, personalised, dynamic and networked. The implication for the learning design field is that more research work needs to focus on the design practices of university teachers to develop an empirically derived evidence base to better understand and thus inform how teachers can be effectively supported in their design work.

\section{References}

Agostinho, S. (2009). Learning design representations to document, model, and share teaching practice. In L. Lockyer, S. Bennett, S. Agostinho, \& B. Harper (Eds.), Handbook of learning design and learning objects: Issues, applications, and technologies (Vol. 1, pp. 1-19). Hershey, PA: IGI Global.

Agostinho, S. (2011). The use of a visual learning design representation to support the design process of teaching in higher education. Australasian Journal of Educational Technology, 27(6), 961-978. http://dx.doi.org/10.14742/ajet.923

Australian Bureau of Statistics. (2001). Appendix. 11. 1272.0 - Australian Standard Classification of Education (ASCED), 2001. Canberra: Author. Retrieved from http://www.abs.gov.au/ausstats/abs@.nsf/0/E6F8F14D6095B959CA256AAF001FCA76?opendocu $\underline{\text { ment }}$

Bennett, S., Agostinho, S., \& Lockyer, L. (2015). Technology tools to support learning design: Implications derived from an investigation of university teachers' design practices. Computers and Education, 81, 211220. https://doi.org/10.1016/j.compedu.2014.10.016

Bennett, S., Agostinho, S. \& Lockyer, L., (2016a). Investigating university educators’ design thinking and the implications for design support tools. Journal of Interactive Media in Education, 2016(1), 1-10. https://doi.org/10.5334/jime.404

Bennett, S., Agostinho, S., \& Lockyer, L. (2016b). The process of designing for learning: Understanding university teachers' design work. Educational Technology Research and Development, 65(1), 1-21. https://doi.org/10.1007/s11423-016-9469-y 
Bennett, S., Thomas, L., Agostinho, S., Lockyer, L., Jones, J., \& Harper, B. (2011). Understanding the design context for Australian university teachers: Implications for the future of learning design. Learning, Media and Technology, 36(2), 151-167. https://doi.org/10.1080/17439884.2011.553622

Bergin, J., Eckstein, J., Manns, M. L., Sharp, H., Chandler, J., Marquardt, C., ... Völter, M. (2012). Pedagogical patterns: Advice for educators. Joseph Bergin Software Tools.

Bradley, D., Noonan, P., Nugent, H., \& Scales, B. (2008). Review of Australian higher education: Final report. Canberra: Commonwealth of Australia. Retrieved from https://www.mq.edu.au/_data/assets/pdf_file/0013/135310/bradley_review_of_australian_higher_educati on.pdf

Conole, G., \& Culver, J. (2010). The design of Cloudworks: Applying social networking practice to foster the exchange of learning and teaching ideas and designs. Computers \& Education, 54(3), 679-692. https://doi.org/10.1016/j.compedu.2009.09.013

Conole, G., \& Wills, S. (2013). Representing learning designs: Making design explicit and shareable. Educational Media International, 50(1), 24-38. https://doi.org/10.1080/09523987.2013.777184

Engeström, Y. (2001). Expansive learning at work: Toward an activity theoretical reconceptualization. Journal of Education and Work, 14(1), 133-156. https://doi.org/10.1080/13639080020028747

Glenn, M. (2008). The future of higher education: How technology will shape learning (A report from the Economist Intelligence Unit, sponsored by the New Media Consortium). Retrieved from http://graphics.eiu.com/upload/the\%20future\%20of\%20universities.pdf

Hernández-Leo, D., Asensio-Pérez, J. I., Derntl, M., Prieto, L. P., \& Chacón, J. (2014). ILDE: Community environment for conceptualizing, authoring and deploying learning activities. In Open learning and teaching in educational communities (pp. 490-493). New York, NY: Springer.

James, R., Bexley, E., Devlin, M., \& Marginson, S. (2007). Australian university student finances 2006: Final report of a national survey of students in public universities. Canberra: Universities Australia. Retrieved from https://www.universitiesaustralia.edu.au/ArticleDocuments/407/Australian University Student Finances 2006.pdf.aspx

Krause, K., Hartley, R., James, R., \& McInnis, C. (2005). The first year experience in Australian universities: Findings from a decade of national studies. Canberra: Department of Education, Science and Training. Retrieved from http://melbourne-cshe.unimelb.edu.au/research/past-research-projects/experience/the-firstyear-experience-in-australian-universities

Laurillard, D. (2012). Teaching as a design science: Building pedagogical patterns for learning and technology. New York, NY: Routledge.

Laurillard, D., Charlton, P., Craft, B., Dimakopoulos, D., Ljubojevic, D., Magoulas, G., ... Whittlestone, K. (2013). A constructionist learning environment for teachers to model learning designs. Journal of Computer Assisted Learning, 29(1), 15-30. https://doi.org/10.1111/j.1365-2729.2011.00458.x

McAndrew, P., \& Goodyear, P. (2013). Representing practitioner experiences through learning designs and patterns. In H. Beetham \& R. Sharpe (Eds.), Rethinking pedagogy for a digital age: Designing for 21st century learning (pp. 133-144). New York, NY: Routledge.

Postareff, L., \& Lindblom-Ylänne, S. (2008). Variation in teachers’ descriptions of teaching: Broadening the understanding of teaching in higher education. Learning and Instruction, 18(2), 109-120. https://doi.org/10.1016/j.learninstruc.2007.01.008

Prosser, M., \& Trigwell, K. (1997). Relations between perceptions of the teaching environment and approaches to teaching. British Journal of Educational Psychology, 67(1), 25-35. https://doi.org/10.1080/03057269908560135

Ramsden, P. (2003). Learning to teach in higher education (2nd ed). London: RoutledgeFalmer.

Razzouk, R., \& Shute, V. (2012). What is design thinking and why is it important? Review of Educational Research, 82(3), 330-348. https://doi.org/10.3102/0034654312457429

Shulman, L. S. (2005). Signature pedagogies in the professions. Daedalus, 134(3), 52-59. https://doi.org/10.1162/0011526054622015

Stark, J. S. (2000). Planning introductory college courses: Content, context and form. Instructional Science, 28(5), 413-438. https://doi.org/10.1007/978-94-010-0593-7 7

Trigwell, K., Prosser, M., \& Waterhouse, F. (1999). Relations between teachers' approaches to teaching and students' approaches to learning. Higher Education, 37(1), 57-70. http://dx.doi.org/10.1023/A:1003548313194 
Corresponding author: Shirley Agostinho, shirleya@uow.edu.au

Australasian Journal of Educational Technology @ 2018.

Please cite as: Agostinho, S., Lockyer, L., \& Bennett, S. (2018). Identifying the characteristics of support Australian university teachers use in their design work: Implications for the learning design field. Australasian Journal of Educational Technology, 34(2), 1-15. https://doi.org/10.14742/ajet.3776 